Nippon Suisan Gakkaishi $\quad \mathbf{5 7 ( 3 )}, 409-415$ (1991)

\title{
Seasonal Patterns of Larval Settlement and Daily Otolith Increments in the Temperate Wrasse Halichoeres tenuispinis
}

\author{
Toshiya Kishiro ${ }^{* 1,2}$ and Akinobu Nakazono*1 \\ (Received July 4, 1990)
}

\begin{abstract}
Seasonal patterns of larval settlement were studied in the temperate wrasse Halichoeres tenuispinis at Tsuyazaki, Fukuoka Prefecture, Japan, during the period from July through November, 1987. The "settlers" (juveniles smaller than $15 \mathrm{~mm}$ TL) started to appear on the rocky reef in late July and increased in number suddenly in early August, attaining more than 600 individuals within the transect $\left(100 \mathrm{~m}^{2}\right)$. The number decreased in late August and the "juveniles" (15-40 mm TL) increased their number in turn. Otolith (sagitta) marking with a fluorescent substance in "juveniles" revealed that the increments are formed daily. Hatched larvae had a clear hatching check in the otoliths. By counting increments exterior to the hatch check in 101 specimens collected during the period from July 27 to September 7, 1987, an equation $\ln Y=0.023 X+1.782$, where $Y=$ total length and $X=$ number of increments, was obtained. It was estimated that the shortest duration of planktonic life in the present species is 26 days after spawning. Back calculated dates of birth of these specimens fell within a relatively short period from June 7 to July 25 .
\end{abstract}

It is reasonable to consider that the number of species and population sizes of reef fishes largely depend on what kinds of fishes settle on that reef and how they survive. For this reason, understanding of mechanisms which decide settlement of larval reef fishes and ecological features which decide their survival is a primary concern for fisheries biology of the reef fishes. However, the fact that many of the reef fishes go through planktonic stages complicates the situation. ${ }^{1-3}$ )

One of the possible approaches may be to monitor the settlement of larval fishes at a relevant reef, as pioneered by Sale and his coworkers. ${ }^{3,4,6-8)}$ The results will sbow the time of the year of settlement and the quantity of larval fishes settling on the reef. ${ }^{\text {) }}$ )

A recent finding that otolith increments of fishes are formed daily ${ }^{10}$ has provided an important technique for analyzing the mechanisms of larval fish recruitment. The duration of planktonic life of reef fishes can be established in days, and many papers estimating the duration of planktonic stages of reef fishes have been published. ${ }^{11-17)}$ For example, Victor ${ }^{15)}$ counted daily increments between the center of the otolith and settlement mark ${ }^{14}$ ) in 100 species of labrids and has shown that the duration of planktonic life differs among species from 15 to 121 days. Most of these papers are, however, treating fishes of coral reefs in tropical or subtropical regions where a large number of species of reef fishes occur on diversified habitats. Studies on the settlment of temperate reef fishes are scarce and information is limited.

The present study aimed to clarify seasonal patterns of larval settlement in Halichoeres tenuispinis, through underwater observations at northern coast of Kyushu. Secondly, it aimed to verify whether the otolith increments found in hatched larvae and settled juveniles are daily rings or not. It also studied whether otoliths of the present species have settlement marks as is reported in many tropical labrid species. $\left.{ }^{14}, 15\right) \quad$ Data from the analysis of otoliths were then used to correlate age and body size of the newly settled juveniles, and to determine their growth rate. Finally, the relationship among the seasonal pattern of settlement, the estimated age of the juveniles and spawning season is discussed.

\section{Materials and Methods}

The temperate wrasse Halichoeres tenuispinis is a small reef fish attaining $15 \mathrm{~cm}$ in total length

*1 Department of Fisheries, Faculty of Agriculture, Kyushu University, Hakozaki, Higashi, Fukuoka 812, Japan (木白俊哉, 中園明信：九州大学震学部水産学科).

*2 Present address: National Research Institute of Far Seas Fisheries, Orido, Shimizu, Shizuoka 424, Japan（現在：遠洋水庭研究所). 


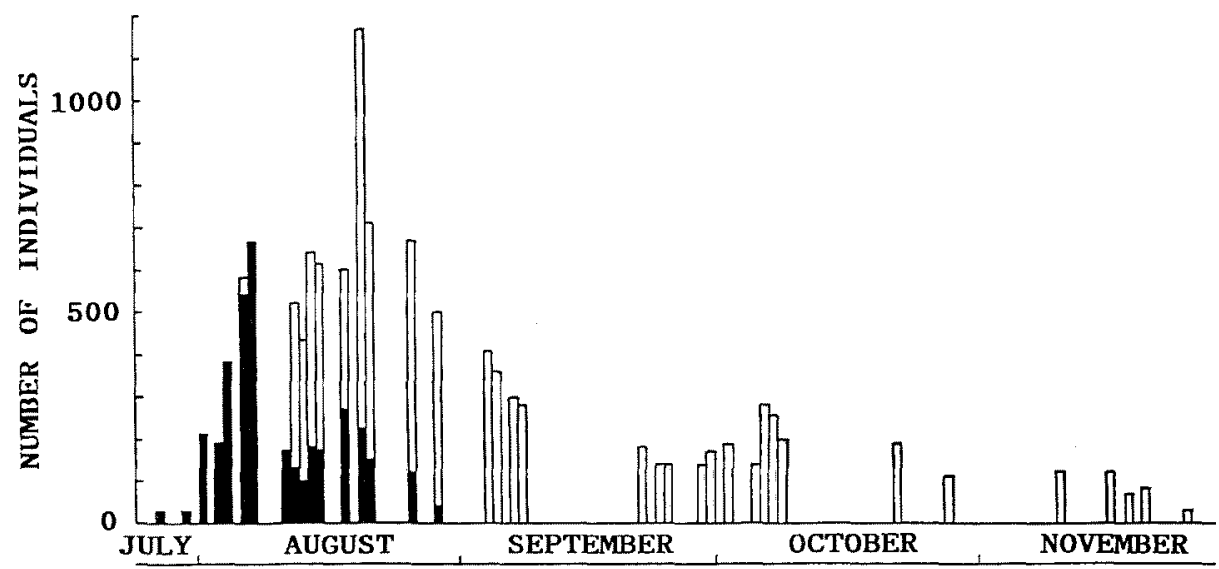

Fig. 1. Seasonal patterns of "settler" (juveniles smaller than $15 \mathrm{~mm}$ TL) and "juvenile" (15$40 \mathrm{~mm}$ TL) occurrence in 1987 expressed by the number of fish observed within the transect $(50 \times 2 \mathrm{~m})$. Solid column; "settler", open column; "juvenile".

(TL), with a maximum age of $3-4$ years. It is the most numerous labrid found around the shallow rocky reefs of Tsuyazaki $\left(33^{\circ} 47^{\prime} \mathrm{N}, 130^{\circ} 29^{\prime} \mathrm{E}\right)$, Fukuoka Prefecture, Japan. According to a census carried out in 1966, the population density was 0.2 ind. $/ \mathrm{m}^{2}{ }^{2}$ ) Although no censuses were attempted thereafter, routine underwater observations by the junior author show that it has been one of the dominant species at the area for more than 20 years. Some features of general ecology of the fish, including the size of home ranges and diurnal activity are available in Nakazono and Tsukahara. ${ }^{18}$ Data on reproductive behavior and on sex change are in Nakazono. ${ }^{10)}$ According to these authors, the spawning season of $H$. tenuispinis starts in carly June and last until early September. Settlement of larvae of ca. $10 \mathrm{~mm} \mathrm{TL}$ occurs in the midst of summer every year.

To elucidate the seasonal pattern of settlement in $H$. tenuispinis, censuses on number of settling fish were carried out near a small island called Tsuzumi-shima (about $100 \mathrm{~m}$ in the longest diameter) near Tsuyazaki, in 1987. The census was done along a $50 \mathrm{~m}$ transect rope set at the northern part of the reef surrounding Tsuzumishima. The transect rope was set from the shallows, $2 \mathrm{~m}$ deep, near the island, offshore to a depth of $7 \mathrm{~m}$ at the end of the rope. As fish were counted they were put visually into two size classes. Those smaller than $15 \mathrm{~mm} \mathrm{TL}$ were termed "settlers" in the present study. Those between 15-40 mm TL were called "juveniles".20) Not only their body sizes but also the translucent body of the "settlers" was employed to discriminate the two. The number of "settlers" and "juveniles" occurring within $1 \mathrm{~m}$ on both sides of the rope was counted as frequently as possible, during the period form July through November, 1987. Those fish smaller than $40 \mathrm{~mm}$ TL retained juvenile body color, especially a black spot on the dorsal fin and on the caudal peduncle. Those fish larger than $40 \mathrm{~mm} \mathrm{TL}$, which had a body color similar to the adult and swam around wider ranges, were omitted from the census.

To prove that otolith increments are daily rings, one lot of 10 "juveniles" was kept in Alizarin complexone (1,2-Dihydroxyanthraquinone-3-ylmethylamine- $\mathrm{N}$, N-diacetic Acid, $\mathrm{C}_{19} \mathrm{H}_{15} \mathrm{NO}_{8}$, Wako Jun-yaku Kogyo Co. Ltd.) solution of $200 \mathrm{ppm}$ concentration for 24 hours, moved to clear seawater for 3 days and again immersed in the solution for 24 hours." Another lot of "juveniles" of the same number was dipped into the solution three times for 24 hours with an interval of 1 day in clear water. These fish were kept frozen and principally left sagittae were taken out later. The sagittae were ground along the long axis on the vertical plane until the core appeared. The number of increments between marked increments was counted under a fluorescent microscope.

A total of 101 "settlers" and "juveniles", ranging from $11.0-31.1 \mathrm{~mm}$ TL was collected, during the period from July 27 to September 7, 1987, by hand net around Tsuzumi-shima, away from the transect rope. They were fixed in $95 \%$ ethanol 
and principally the left sagittae were taken out later. These sagittae were ground as the same manner as the above and were slightly etched with $\mathrm{HCl}$ adjusted to $\mathrm{pH} 3$. Each increment is composed of a wider light line and a following narrower dark line. ${ }^{22)}$ In the present study, the number of the light lines occurring exterior to the first dark line was counted under a microscope.

To confirm that this first dark line is a hatch check, ${ }^{23)}$ artificial insemeination of the eggs was carried out in 1990. The hatched larvae were kept in a $30 /$ tank under the natural photoperiod until the next day. The sagittae on the day of hatching and one day after hatching were observed, slighly smashing the fish under a cover glass. The longest diameters of the first dark ring in the sagittae of hatched larvae and those of settled juveniles were compared.

\section{Results}

\section{Seasonal Pattern of Larval Settlement}

Seasonal change in the number of "settlers" and "juveniles" of Halichoeres tenuispinis observed within the transect, covering $100 \mathrm{~m}^{2}$, are shown in Fig. 1. The "settlers" occurred within the same habitat as adults, but usually stayed in schools of various sizes among the thichets of brown algae or in the recesses of rocks, apart from adults. The first occurrence of "settlers" at the transect was noted on July 27. Their number increased suddenly to more than $600 \mathrm{fish} / 100 \mathrm{~m}^{2}$ by August 7, but decreased gradually afterward. Only one individual was observed on September

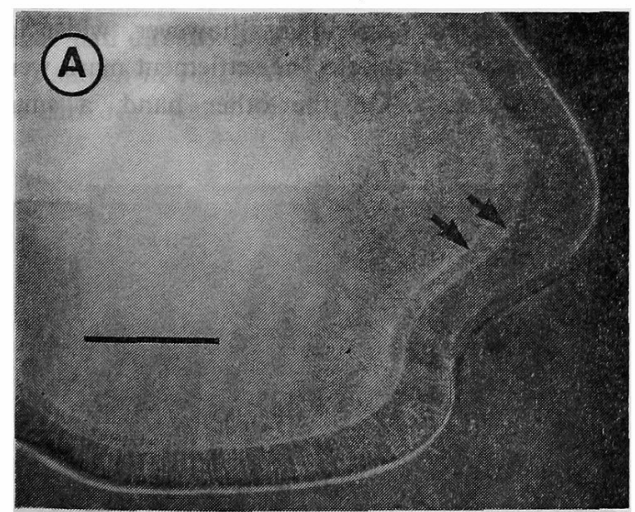

22 and 24 , respectively. These results show that a large scale settlement takes place within a short period from late July ot late August, with a maximum in early August.

The first appearance of the "juveniles" was on August 4, but a large number initially occurred on August 12. The numbers of the "juveniles" remained between $277-588$ individuals in the transect during the period from August 12 through September 4, except for one datum on August 20. The number of the "juveniles" also decreased during the period from September 5 through 22 . The delay in the appearance of "juveniles" is in accordance with the growth rate of settled fish, i.e. it takes about 13 days for a "settler" of $11 \mathrm{~mm}$ TL to grow to $15 \mathrm{~mm} \mathrm{TL}$ (see below). After September 22, the number of "juveniles" was relatively constant at $146 \pm 68(\bar{x}$ and SD of latter 17 censuses), suggesting that a small scale settlement was still continuing after the burst of settlement in August, although "settlers" were hardly seen in the transect.

\section{Otolith Marking}

A typical sagitta marked with Alizarin complexone with an interval of 3 days is shown in Fig. 2A. The same sagitta ground on the vertical plane along the long axis until the level of the core is shown in Fig. 2B. As is shown in Fig. 2B with arrows, three light lines are visible between the two lines stained with Alizarin complexone. Results of otolith marking in the two lots of 10 fishes are summarized in Table 1 . Among 10 fish stained with an interval of 3 days, 9 had three

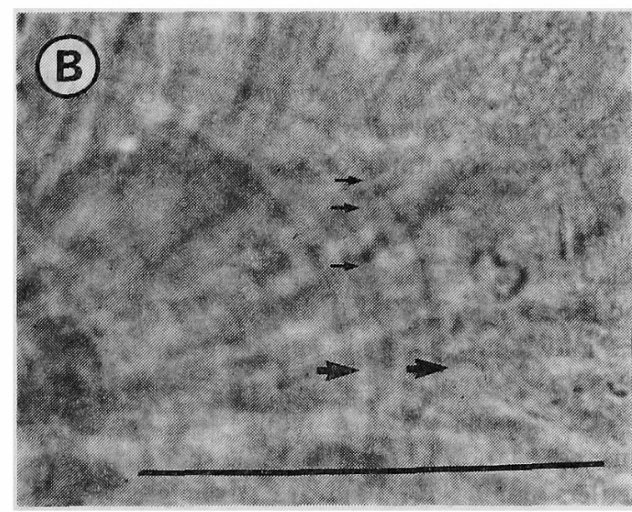

Fig. 2. Photomicrograph of an Alizarin complexone stained sagitta of Halichoeres tenuispinis. Scale bar indicates $50 \mu \mathrm{m}$.

A; Two stained marks (arrows) are clearly seen under fluorescent lighting.

B; The same sagitta ground and observed under normal and fluorescent light together. Three small arrows show increments between stained two marks indicated with large two arrows. 
Table 1. Results of Alizarin complexone marking in Halichoeres tenuispinis juveniles

\begin{tabular}{cccc}
\hline \hline No, & Total length & $\begin{array}{c}\text { Length of major } \\
\text { axis of sagitta }\end{array}$ & $\begin{array}{c}\text { Number of increments } \\
\text { between marks }\end{array}$ \\
\hline Marking with 3-day interval & & 3 \\
1 & $18.5 \mathrm{~mm}$ & $574 \mu \mathrm{m}$ & $?$ \\
2 & 19.0 & 545 & 3 \\
3 & 19.5 & 586 & 3 \\
4 & 20.5 & 568 & 3 \\
5 & 21.0 & 571 & 3 \\
6 & 21.0 & 599 & 3 \\
7 & 22.0 & 610 & 3 \\
8 & 23.0 & 589 & 3 \\
9 & 24.0 & 650 & 3 \\
10 & 25.5 & 692 & 1 \\
Marking with 1-day interval & & 1 \\
1 & 15.5 & 438 & $?$ \\
2 & 15.5 & 468 & $?$ \\
3 & 15.5 & 498 & 1 \\
4 & 16.0 & 485 & 1 \\
5 & 18.0 & 544 & 1 \\
6 & 19.5 & 571 & 1 \\
7 & 22.0 & 581 & 1 \\
8 & 22.0 & 631 & 1 \\
9 & 26.0 & 688 & \\
10 & 27.0 & 671 & \\
\hline
\end{tabular}

?; Uncountable because increments were not clear.

lines between the two stained lines. In the remaining one, lines were uncountable, due to lack of clarity. Results were almost the same in 10 fish stained three times with an interval of 1 day, one increment being recognized between each pair of stained lines.

These results show that the increments in the sagittae of $H$. tenuispinis ranging from 15.5$27.0 \mathrm{~mm}$ TL are formed daily.

Number of Otolith Increments and Growth of "Settlers" and "Juveniles"

A photomicrograph of the ground sagitta is shown in Fig. 3. Thirty eight increments were countable in this specimen under a microscope. Relationship between the number of increments and the total length of 101 fish is shown in Fig. 4. The individual values fit well to the curve $\ln Y=$ $0.023 X+1.782$ with $r=0.929 \quad(P<0.001)$, where $Y=\mathrm{TL}$ in $\mathrm{mm}$ and $X=$ number of increments. This correlation shows that the body sizes of "settlers" and "juveniles" are strongly correlated with the number of increments in otoliths. The correlation also shows that the growth of newly settling fish is slow just after they have appeared on the reef, but they grow faster after they attain $15 \mathrm{~mm}$ TL. It takes only 30 days for a "juvenile" of $15 \mathrm{~mm}$ TL to double its body length.

In many species of labrids, it has been shown that there are a few wider increments corresponding to the period when the larvae are buried in the sand to metamorphose before they appear on the reef. ${ }^{14)}$ This is referred to as a settlement mark and similar disturbances in otolith increments are found in many other reef fishes. ${ }^{13,15-17)}$ In $H$. tenuispinis specimens, however, wider increments comparable to the settlement mark were not recognized. On the other hand, a small

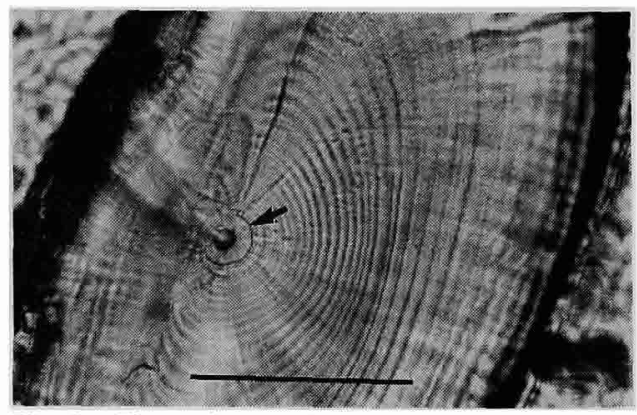

Fig. 3. Photomicrograph of a ground sagitta showing increments and hatch check (arrow). $14.5 \mathrm{~mm}$ TL. Scale bar indicates $50 \mu \mathrm{m}$. 


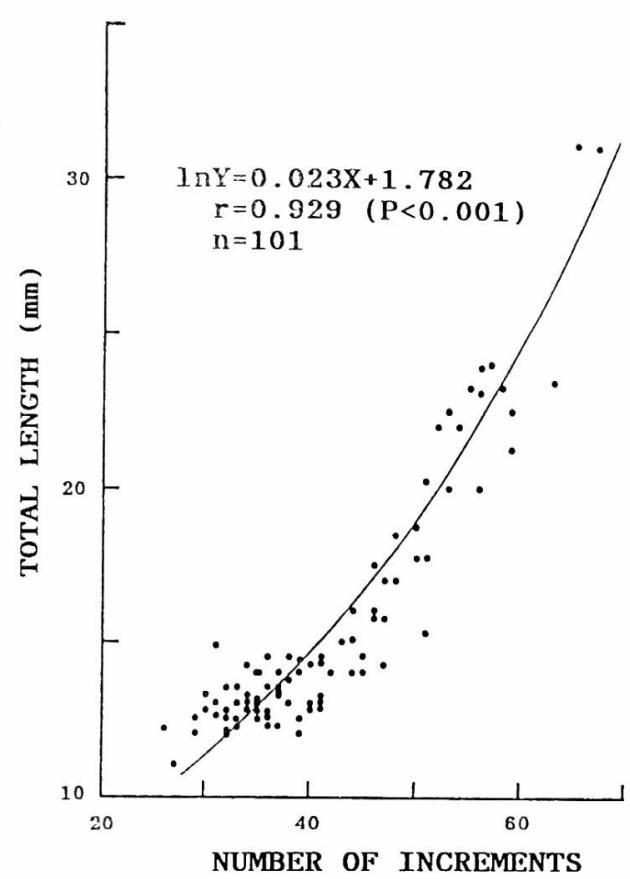

Fig. 4. Relationship between total length of the fish (Y) and number of otolith increments (X). Line is written with hand.

number of sagittae $(27.6 \%$ of 87 sagittae observed) had a narrow increment at 20.4th $\pm 3.7(\bar{x}$ and $\mathrm{SD}, \mathrm{n}=24$ ) increment (Fig. 5).

\section{Hatch Check and Estimated Date of Birth}

The eggs of $H$. tenuispinis hatch within 24 hours in the summer spawning season. The hatched larvae had already one dark line in their sagittae as is shown in Fig. 6A. The longest diameter of the dark ring was $7.84 \pm 0.15 \mu \mathrm{m}(\mathrm{n}=5)$ and was

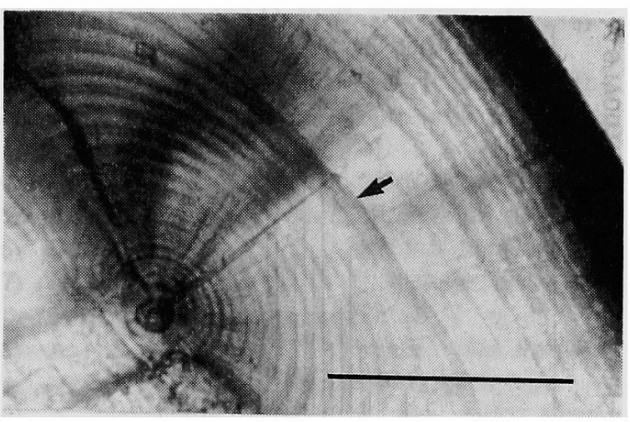

Fig. 5. Photomicrograph of a sagitta having a narrow increment (arrow). $13.5 \mathrm{~mm} \mathrm{TL}$. Scale bar indicates $50 \mu \mathrm{m}$.

close to that of the first strong dark line found in the sagittae of the "settlers" and "juveniles" $(8.44 \pm 0.71 \mu \mathrm{m}, \mathrm{n}=5)$. These results suggested that the first strong dark line found in the sagittae of $H$. tenuispinis is a hatch check. On the next day of hatching, one dark and two light lines were visible exterior to the hatch check (Fig. 6B), suggesting that the increments were formed daily just after hatching. It is not known if the increments are formed daily when the fish is planktonic, but the above results strongly suggest it can be the case. Dates of birth (spawning) of 101 specimens were back calculated, assuming that increments are daily in the planktonic stages. Fig. 7 shows the frequency distribution of the date of birth. The estimated dates of birth of these specimens fell between June 7 and July 25 . These results show that the present specimens collected during the period from late July to early September are largely originating from eggs spawned during the period from the middle of June to the middle of July.
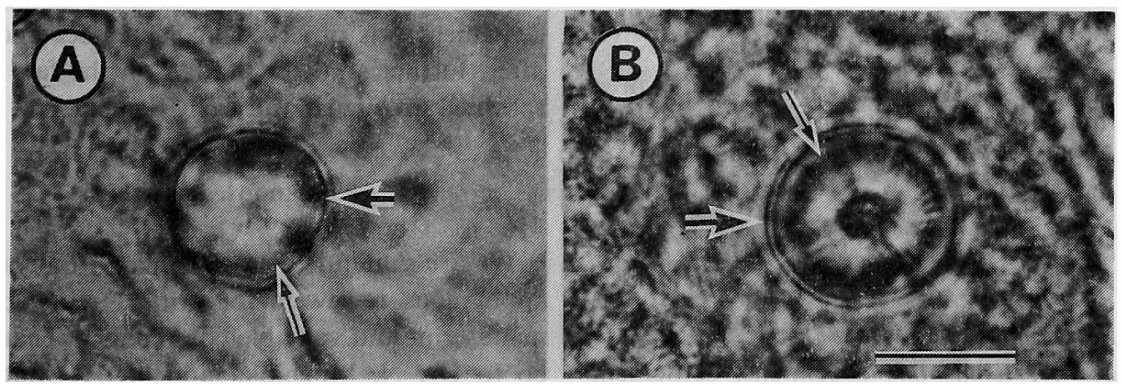

Fig. 6. Sagitta of hatched larva of Halichoeres tenuispinis. Scale bar indicates $10 \mu \mathrm{m}$. Large arrow shows outer margin of otolith. Small arrow shows hatch check.

A: Sagitta on the day of hatching. B: Sagitta on the next day of hatching. One dark and two light lines are visible exterior to the hatch check. 


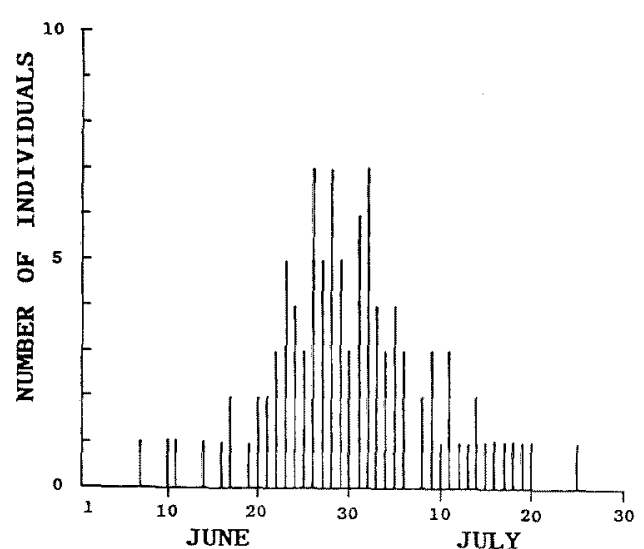

Fig. 7. Frequency distribution of estimated dates of birth (spawning) in 101 Halichoeres tenuispinis.

\section{Discussion}

\section{Settlement Pattern}

In the present study, the seasonal patterns of settlement in the temperate wrasse Halichoeres tenuispinis were studied. It showed that intense settlement takes place in early August. Our routine observations show that settlement of $H$. tenuispinis occurs in each year during this period with a slight annual variation, for example in the middle of August in 1986, and in early August in 1989.*1 Intense settlement within a relatively short period of time can be a norm in $H$. tenuispinis. Contrary to this, the spawning season last three months from early June to early September. The settlement during less than 3 weeks is also found in a labrid living in the Gulf of Maine.*2 These features are different from the results in Caribbean bluchead wrasse Thalassoma bifasciatum, in which settlement takes place many times over a year in accordance with its long spawning season. "s)

Monitoring of "juveniles" as the same area revealed that the number of "juveniles" increased to the same level as that of "settlers", about 10 days after the burst of settlement. These results suggest that the "juveniles" are originating from the "settlers" appearing in August.

\section{Lack of Settlement Mark}

In many $H$. tenuispinis specimens, settlement marks in otoliths, reported in many other lab- rids, ${ }^{15)}$ were not recognized. This may be a reflection that the present species has a different life history pattern when compared with many other labrids. Narrow increments were observed at the 20.4 th increment in $27.6 \%$ of the sagittae. This is about 6 days earlier than the age of the youngest "settler" collected in the present study. However, the lack of this band in the otoliths of many other individuals precludes considering this disturbance as a reliable settlement mark.

\section{Estimation of Duration of Planktonic Stage}

The facts that increments are formed daily in hatched larvae and in "juveniles" of $H$. tenuispinis strongly suggest that increments are daily in planktonic stages. However, the settlement mark was not clear, as stated above, in the present species. For this reason, the duration of planktonic stage could not be determined by only counting increments between the center and the settlement mark in otoliths. It is also not known whether "settlers" settle at the same size or not. However, the smallest number of increments of 26 in a "settler" will represents the shortest duration of the planktonic life in the present species.

It has been reported that daily increments of some other fishes are formed with an interval of $24 \mathrm{hr} 50 \mathrm{~min} .^{24,25)}$ If this is the case for the present species, the error may be negligible for the estimation of the duration of planktonic stage in $H$. tenuispinis, because it results in deviation of only 1 day in a 28.8 day period.

\section{Relationship between Estimated Date of Birth and Spawning Season}

The spawning season of $H$. tenuispinis is form early June to early September. In spite of this, estimated dates of birth of "settlers" and "juveniles" collected in the present study fell between June 7 and July 25 . Because no large scale settlement was observed in September and thereafter, further study is needed on the fate of eggs spawned in August and early September.

\section{Acknowletgments}

We are grateful to Prof. Peter F. Sale and two anonymous reviewers for critical reading of the manuscript and valuable comments. Thanks also go to Dr. N. Mochioka and Mr. T. Matoba for assisting otolith observations, and to $\mathrm{Mr}$. T.

*1 Unpublished data.

* Sale, personal communication. 
Furukawa, the Captain of the Research Boat "Wakasugi", for assisting the research. Thanks are due to Fisheries Cooperative Association of * Tsuyazaki for understanding the purpose of the study and permitting diving at Tsuyazaki.

\section{References}

1) D. R. Kobayashi: Mar. Biol., 100, 285-293 (1989).

2) P. F. Sale: Env. Biol. Fish., 3, 85-102 (1978).

3) P. F. Sale: Oceanogr. Mar. Biol. Ann. Rev., 18, 367-421 (1980).

4) P. F. Sale: Env. Biol. Fish., 21, 3-15 (1988).

5) B. C. Victor: Ecol. Monogr., 56, 145-160 (1986).

6) P. F. Sale, P. J. Doherty, G. J. Eckert, W. A. Douglas, and D. J. Ferrell: Oecologia, 64, 191198 (1984).

7) P.F. Sale: Proc. 5th Int. Coral Reef Congr., Tahiti, 5, 391-396 (1985).

8) D. McB. Williams and P. F. Sale: Mar. Biol., 65, 245-253 (1981).

9) D. R. Robertson, D. G. Green, and B. C. Victor: Ecology, 69, 370-381 (1988).

10) G. Pannella: Science, 173, 1124-1126 (1971).
11) P. J. Doherty and D. McB. Williams: Oceanogr. Mar. Biol. Ann. Rev., 26, 487-551 (1988).

12) A. J. Fowler: Mar. Biol., 102, 167-181 (1989).

13) R. E. Thresher, P. L. Colin, and L. J. Bell: Copeia, 1989, 420-434 (1989).

14) B. C. Victor: Mar. Biol., 71, 203-208 (1982).

15) B. C. Victor: Mar. Biol., 90, 317-326 (1986).

16) B. C. Victor: Mar. Biol., 95, 145-152 (1987).

17) G. M. Wellington and B. C. Victor: Mar. Biol., 101, 557-567 (1989).

18) A. Nakazono and H. Tsukahara: Sci. Bull. Fac. Agr., Kyushu Univ., 26, 583-593 (1972).

19) A. Nakazono: Rep. Fish. Res. Lab., Kyushu Univ., 4, 1-64 (1979).

20) X. Honnma and S. Murakawa: Saishuu to Shiiku, 20, 99-101 (1954).

21) K. Tsukamoto: Nippon Suisan Gakkaishi, 54, 1289-1295 (1988).

22) N. Watabe, K. Tanaka, J. Yamada, and J. M. Dean: J. exp. mar. Biol, Ecol, 58, 127-134 (1982).

23) K. Tsukamoto and T. Kajihara: Nippon Suisan Gakkaishi, 53, 1985-1997 (1987).

24) M. Takahashi: Earth Science, 37, 1-7 (1983).

25) K. Tsukamoto: Nippon Suisan Gakkaishi, 55, 1017-1021 (1989). 